TAPROBANICA, ISSN 1800-427X. April, 2009. Vol. 01, No. 01: pp. 63-65.

(C) Taprobanica Nature Conservation Society, 146, Kendalanda, Homagama, Sri Lanka.

\title{
NOTES ON EX-SITU INCUBATION AND HATCHLINGS OF Eutropis carinata (SCHNEIDER, 1801) (REPTILIA: SCINCIDAE) FROM SRI LANKA
}

Submitted: 03 January 2009, Accepted: 05 January 2009

\author{
Thilina P. Walikanna ${ }^{1}$ and D. M. S. Suranjan Karunarathna ${ }^{2}$ \\ ${ }^{1}$ The Young Zoologists’ Association, Department of National Zoological Gardens, Dehiwala, Sri Lanka \\ ${ }^{2}$ IUCN - Sri Lanka Country office, No: 53, Horton place, Colombo 07, Sri Lanka \\ ${ }^{2}$ Corresponding author: dmsameera@gmail.com
}

\begin{abstract}
Eutropis carinata is widely distributed skink in Sri Lanka. This observation describes ex-situ incubation and hatching of this species at Colombo district in Sri Lanka. In total, 25 eggs with two adults of E. carinata were located from a termite mound while some villagers where trying to kill a cobra (Naja naja) living in the mound. Of these skink eggs, 20 were successfully incubated. The incubation period was 30 days from the date eggs were collected. The average incubation temperature varied from $26-28^{\circ} \mathrm{C}$. Mean egg length was $15.6 \mathrm{~mm}$ and mean egg width $10.4 \mathrm{~mm}$. Mean hatchling SVL was $28.5 \mathrm{~mm}$ and mean TL is $41.3 \mathrm{~mm}$. The mean weight of hatchlings was $\sim 3 \mathrm{~g}$ and the mean total length is $69.8 \mathrm{~mm}$. After about five days, hatchlings were released at the original place of the clutch.
\end{abstract}

Key Words: Eutropis carinata, ex-situ incubation, egg hatching, conservation, Sri Lanka

\section{Introduction}

The genus Eutropis in Sri Lanka consists of seven species: E. beddomei, E. bibronii, E. carinata, E. floweri, E. macularia, E. madaraszi and E. tammanna (Deraniyagala, 1953; Das \& de Silva, 2005; Das et al., 2008). The Common Skink, Eutropis carinata (Schneider, 1801) is known locally in Sinhala as "Sulaba Garandi Hikanala". This species is the largest skink in Sri Lanka (de Silva, 1996, 2006). According to the published literature, E. carinata has been widely distributed in Sri Lanka. The habitats are characterized as open areas, forests with close canopies, home gardens as well as plantations in wet and dry zones below 1,000 m a.s.l. (Das \& de Silva, 2005). Adults of $E$. carinata measured from snout to vent of $140<\mathrm{mm}$, a head length of $25<\mathrm{mm}$, a tail length of $200<\mathrm{mm}$ and an axilla to groin length of $100<\mathrm{mm}$ (Deraniyagala, 1953). The present communication 
adds to our current knowledge on ex-situ incubation and hatching of E. carinata.

Methods of incubation: An enclosure is built of 5 $\mathrm{mm}$ thick, waterproof glass and these form the base, the front, the back and both sides. The top consists of extruded plastic fly screen framing and this allows free flow of air but can be covered with plastic sheeting to increase humidity if desired. The lid is close fitting to protect the eggs from predators. The length of the enclosure is $30 \mathrm{~cm}$, width $15 \mathrm{~cm}$ and height $10 \mathrm{~cm}$. A thermometer and a hygrometer are used to monitor temperature and relative humidity fluctuations. The base of the unit is filled with soil mixed with sand to a depth of nearly $4 \mathrm{~cm}$. A few pieces of stones and leaf litter were also provided as places of concealment for hatchlings.

The relative humidity varied between about 60 $74 \%$ during the month of incubation. These values may be much higher than those found in the open in the wild. The surface soil was normally kept dry but occasionally about $30 \mathrm{ml}$ of water was sprayed in to the hatching device to simulate more natural conditions. The temperature range was $26-28^{\circ} \mathrm{C}$. The daily variation varied about $1-2^{\circ} \mathrm{C}$. The 25 incubating eggs were half-buried in the soil and covered with leaf litter. After about five days, the hatchlings were released to the original habitat.

\section{Observations}

On the 30 January 2008 we found 25 eggs, inside a termite mound at 10:30 hr. The eggs were incubated in Colombo district in Sri Lanka. Of the 25 eggs, 20 were successfully incubated. The incubation period was 30 days from the date eggs were captured, at an average incubation temperature of around $27^{\circ} \mathrm{C}$ (range $26-28^{\circ} \mathrm{C}$ ). The mean length of the eggs was $15.6 \mathrm{~mm}$ (range 13.7-18.0 mm) and mean width was $10.4 \mathrm{~mm}$ (range 9.2-14.8 mm) (Fig. 1).

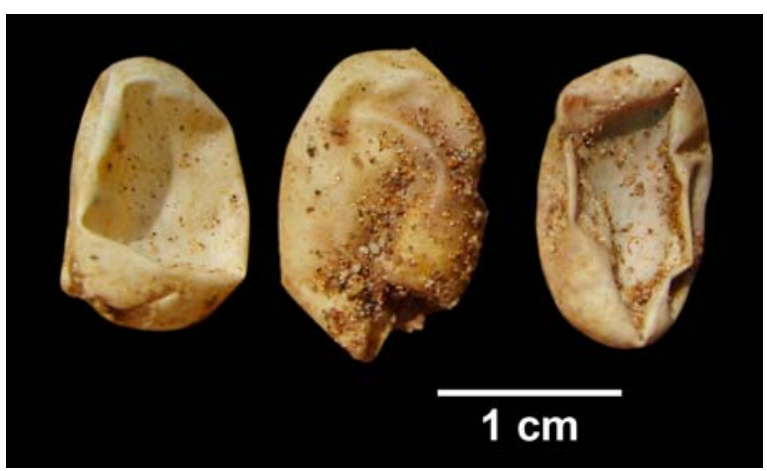

Fig. 01: Three of 20 hatched E. carinata eggs
Measurements of the eggs and hatchling data are presented in the Table 01. The mean SVL of the hatchlings was $28.5 \mathrm{~mm}$ (range $26.2-30.2 \mathrm{~mm}$ ) and mean TL was $41.3 \mathrm{~mm}$ (range 36.5-46.3 mm) (Fig. 2 ). The mean weight of the hatchlings was $\sim 3 \mathrm{~g}$ (based on 10 specimens) (range 4-6 g) and the mean total length was $69.8 \mathrm{~mm}$ (range 62.7-76.5 $\mathrm{mm})$.

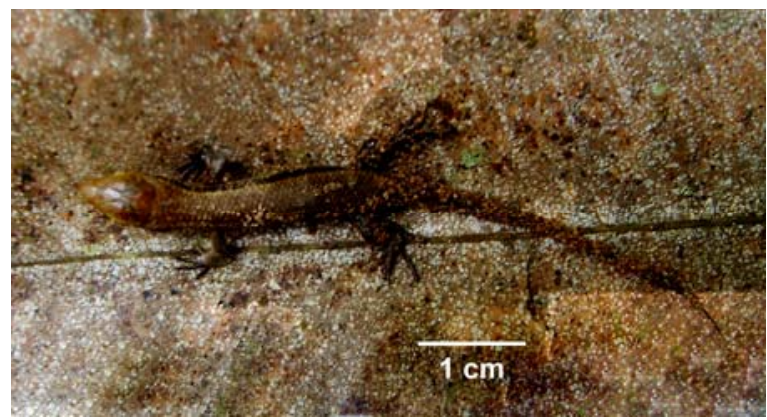

Fig. 02: Newly hatched E. carinata

\section{Discussion}

We have located 25 eggs with two adults (the male and the female) while some villagers were trying to kill a cobra (Naja naja) living in a termite mound. The cobra was about $1.5 \mathrm{~m}$ total length and the two skinks and eggs were present in this termite mound. The interesting fact about this observation is that this is probably the first record of E. carinata from a termite mound which inhabited by a cobra. This is the first documented hatching of $E$. carinata eggs observed from Sri Lanka. Sometimes E. carinata and $N$. naja may show commensalism; however, there are no previous records of this kind of behaviour for E. carinata. Somehow, it is a better habitat for E. carinata to live with a $N$. naja in a termite hole, because we assume that other snakes, especially Ptyas mucosa, Cercaspis carinata, Olidodon arnensis, Lycodon aulicus, Boiga ceylonensis, Hypnale hypnale and Dendelaphis tristris, never reach there because the ophiophagous Naja naja is one of their natural predators. In addition, Varanus bengalensis and some birds like White breasted King fisher (Halcyon smyrnensis), Gray horn bill (Ocyceros gingalensis), Shikra (Accipiter badius) and Little Scops Owl (Otus bakkamoena) are natural predators of E. carinata.

It is not clear for us why Naja naja refrain from feeding on $E$. carinata adults living inside the same termite hole. We have observed Naja naja feed on toads, other snakes, Naja naja, juveniles of Varanus bengalensis as well as agamid lizards, but we never observed Naja naja feeds on skinks before, but skinks were swallowed by cobra as well as Ceylon 
krait, Bungarus ceylonicus (A. de Silva, November 2008, pers. comm.). Sometimes the skink may use another root to enter the termite mound where those eggs were deposited. However we could not examine the entire hole because while we reach there the villagers had broken a half of the termite mound. According to the perused literature information on behaviors, feeding and breeding habits, population dynamics, ecology and threats are not properly understood for most species in Sri Lanka (Amarasinghe, 2009). Therefore, we believe that this information on ex-situ incubation and hatching of E. carinata may facilitate the future conservation of this species as well as other skinks.

Table 01. Measurements of eggs and hatchlings of Eutropis carinata (NH: not hatched; SVL: Snout-Vent length; TL: Tail length)

\begin{tabular}{|c|c|c|c|c|}
\hline \multirow[t]{2}{*}{ No. } & \multicolumn{2}{|c|}{ Egg size (mm) } & \multicolumn{2}{|c|}{$\begin{array}{l}\text { Hatchling size } \\
\text { (mm) }\end{array}$} \\
\hline & Length & Width & SVL & TL \\
\hline 1 & 15.2 & 9.8 & 28.4 & 42.3 \\
\hline 2 & 13.7 & 11.6 & 26.2 & 36.5 \\
\hline 3 & 16.3 & 14.8 & 29.1 & 38.7 \\
\hline 4 & 18 & 9.7 & 30.2 & 46.3 \\
\hline 5 & 15.1 & 11.9 & 28.1 & 41.7 \\
\hline 6 & 15.5 & 11.3 & 28.3 & 42 \\
\hline 7 & 16.2 & 9.9 & 28.8 & 43.5 \\
\hline 8 & 15.1 & 9.8 & \multicolumn{2}{|c|}{$\mathrm{NH}$} \\
\hline 9 & 16.5 & 9.2 & 29.1 & 42.4 \\
\hline 10 & 15.7 & 10.6 & 28.2 & 41.1 \\
\hline 11 & 15.5 & 9.7 & \multicolumn{2}{|c|}{$\mathrm{NH}$} \\
\hline 12 & 17.1 & 9.9 & 29.8 & 43.7 \\
\hline 13 & 14.7 & 9.6 & 27.4 & 37.7 \\
\hline 14 & 15.5 & 9.8 & 29.1 & 41.7 \\
\hline 15 & 15.8 & 9.5 & 29.7 & 42.1 \\
\hline 16 & 14.9 & 9.7 & 27.2 & 38.3 \\
\hline 17 & 15.8 & 9.6 & 28.6 & 42.3 \\
\hline 18 & 15.2 & 9.8 & \multicolumn{2}{|c|}{$\mathrm{NH}$} \\
\hline 19 & 15.4 & 9.7 & 28.2 & 41.6 \\
\hline 20 & 17 & 9.4 & 29.8 & 42.4 \\
\hline 21 & 14.3 & 11.2 & 27.2 & 37.6 \\
\hline 22 & 13.8 & 10.7 & \multicolumn{2}{|c|}{$\mathrm{NH}$} \\
\hline 23 & 15.8 & 11.2 & \multicolumn{2}{|c|}{$\mathrm{NH}$} \\
\hline 24 & 15.1 & 10.5 & 28.4 & 42.2 \\
\hline 25 & 15.7 & 10.2 & 28.8 & 41.4 \\
\hline Mean & 15.6 & 10.4 & 28.5 & 41.3 \\
\hline
\end{tabular}

\section{Acknowledgments}

The authors wish to thank Indraneil Das, Enrique La Marca and Anslem de Silva for reviewing the manuscript and Mohomed M. Bahir for his valuable comments and Mendis Wickramasinghe (SLHS) is also acknowledged for his comments. Finally, we would like to thank Thasun Amarasinghe (TNCS) and Niranjan Karunarathna for their supports.

\section{Literature Cited}

Amarasinghe, A. A. T., 2009. Editorial; An introduction to Taprobanica. Taprobanica, 1 (1): 1.

Das, I., A. de Silva, and C. C. Austin, 2008. A new species of Eutropis (Squamata: Scincidae) from Sri Lanka. Zootaxa, 1700: 35-52.

Das, I. and A. de Silva, 2005. Photographic Guide to Snakes and other Reptiles of Sri Lanka. New Holland Publishers (UK) Ltd., London: 144.

Deraniyagala, P. E. P., 1953. A Colored Atlas of some vertebrates from Ceylon, Vol. 2, Tetrapod Reptilia, National Museums of Sri Lanka, Colombo: 101.

de Silva, A., 1996. The Herpetofauna of Sri Lanka: a brief review. Graphic Land, Kandy. Published by Author: 99.

de Silva, A., 2006. Current status of the reptiles of Sri Lanka. In: Fauna of Sri Lanka: Status of Taxonomy, Research and Conservation. 134-163. C.N.B. Bambaradeniya (Ed.). The World Conservation Union, Colombo, Sri Lanka and Government of Sri Lanka. 